\title{
Slowing The Revolving Door: Looking For New Keys To Retain ENTRY-Level Retall Workers
}

\author{
D. Michael Fields \\ Southwest Missouri State University \\ Springfield, Missouri \\ Stella M. Nkomo \\ University of North Carolina at Charlotte \\ Charlotte, North Carolina
}

\section{Introduction}

Retailers entered the 1990 s struggling with a problem most had not previously faced-the availability of entry-level labor. During the 1980s, retailers became increasingly dependent on the young worker to staff the ever-growing number of part-time, entry-level positions-unaware that trends that demographers had spotted 20 years before were about to have a severe impact on their ability to service their customers. Beginning in 1979, and continuing almost uninterrupted into the 1990 s, there were fewer potential workers in the 16-24 age group than there had been in each succeeding year. The result of this reoccurring reduction was first felt in the fast food industry in the mid-1980s. By the end of the decade, the problem plagued the entire retail sector.

Retailers have been scrambling to survive what has become a serious labor shortage. Although some efforts have been expended to recruit nontraditional workers (e.g., handicapped and elderly), a bidding war for the typical worker has ensued. Workers have responded to the escalating wage rate and increasing benefits by moving from job to job at previously unrecorded rates. Many retailers have become a virtual revolving door for personnel. This skyrocketing turnover has caused retailers to spend substantially more time and money recruiting and training new employees as well as to question the level of service that these personnel are providing their customers.

For retailers to succeed in this seller's labor market, they must find ways other than the increase of wages and benefits in order to retain new employees. A possible option is to better understand the job expectations of potential employees. The ideal situation would be for a retailer to be able to isolate differences in job expectations between identifiable groups. By knowing these differing expectations, the retailers could tailor their internal environment to better match the expectations of targeted employees and/or hire employees from the groups that have more realistic employment expectations.

The primary purpose of the present study is to identify the relative importance of several job and company characteristics to newly hired retail employees. A secondary objective is to determine if corresponding generalizations regarding these characteristics might be supported across retailers. Information was gathered from employees from a department store, a specialty store, and a supermarket early in the individual's first week of employment. The newly hired employees were asked a series 
of questions regarding the degree of importance for certain characteristics in their selection of a job and the likelihood that their new employer would be able to provide each of these characteristics. Differences between employee groups among the three companies as well as differences between the employees of the three differing retailens were examined.

\section{Background}

In the 1960s, when retailers had an entry-level sales opening, selection could be as simple as pulling an application from a large stack that was almost certainly on hand. As increasing numbers of baby boomers (those born between 1946-1964) reached working age, the supply of workers increased. This abundant supply afforded employers several advantages. First, the wages for hourly personnel were suppressed, often being defined by the prevailing minimum wage. Second, corresponding benefits offered employees were very limited. Third, turnover was low because of the difficulty in finding replacement jobs. Fourth, employers could exercise more selectivity in filling these job openings when they did occur. Fifth, management could utilize an authoritarian style to emphasize the attainment of company oriented goals. Finally, many retailers were able to increase their percentage of part-time workers.

Several benefits were associated with this increased use of part-imers. The primary advantage was the opportunity to reduce both direct (lower wage rates) and indirect (less benefits) labor costs. An additional benefit was that a large contingent of part-time workers allowed the retailer greater scheduling flexibility. Workers could be scheduled to better match demand peaks and to meet the increased demands of longer hours as retailers continued their suburban development. Finally, the use of part-time employees made it easier to specialize among job tasks [10].

During the $1970 \mathrm{~s}$, although retailers continued to need additional numbers of workens, the uninterrupted increase in the supply of young workers ended (See Figure 1). However, there were sufficient numbers seeking jobs to fill both the existing positions and these new jobs that a growing retail sector developed. Retailers, which had become increasingly dependent on the young worker (16-24) to staff their stores, continued to utilize a larger percentage of part-time workers. This trend can be seen by examining the average hours per week for the non-supervisory retail worker (See Figure 2).

For some sectors of retailing, declining productivity has further worsened the problem. For those areas of retailing for which data are available, both eating and drinking places and food stores suffered average annual productivity declines. As a result of this situation, these retailers are increasingly reliant upon labor to meet the higher output requirements [4].

As retailers entered the 1980 s, researchers began to isolate differences between the full-time worker and the part-time employee that could be potential sources of concern for the employers. The research has shown that part-time personnel will not only leave their jobs more often than will full-timers, but they will leave because of external reasons while full-timers tend to separate because of job related reasons [6]. Also, 
Figure 1: Supply of Young Workers rs. Demand

for Non-Supervisory Retail Employees

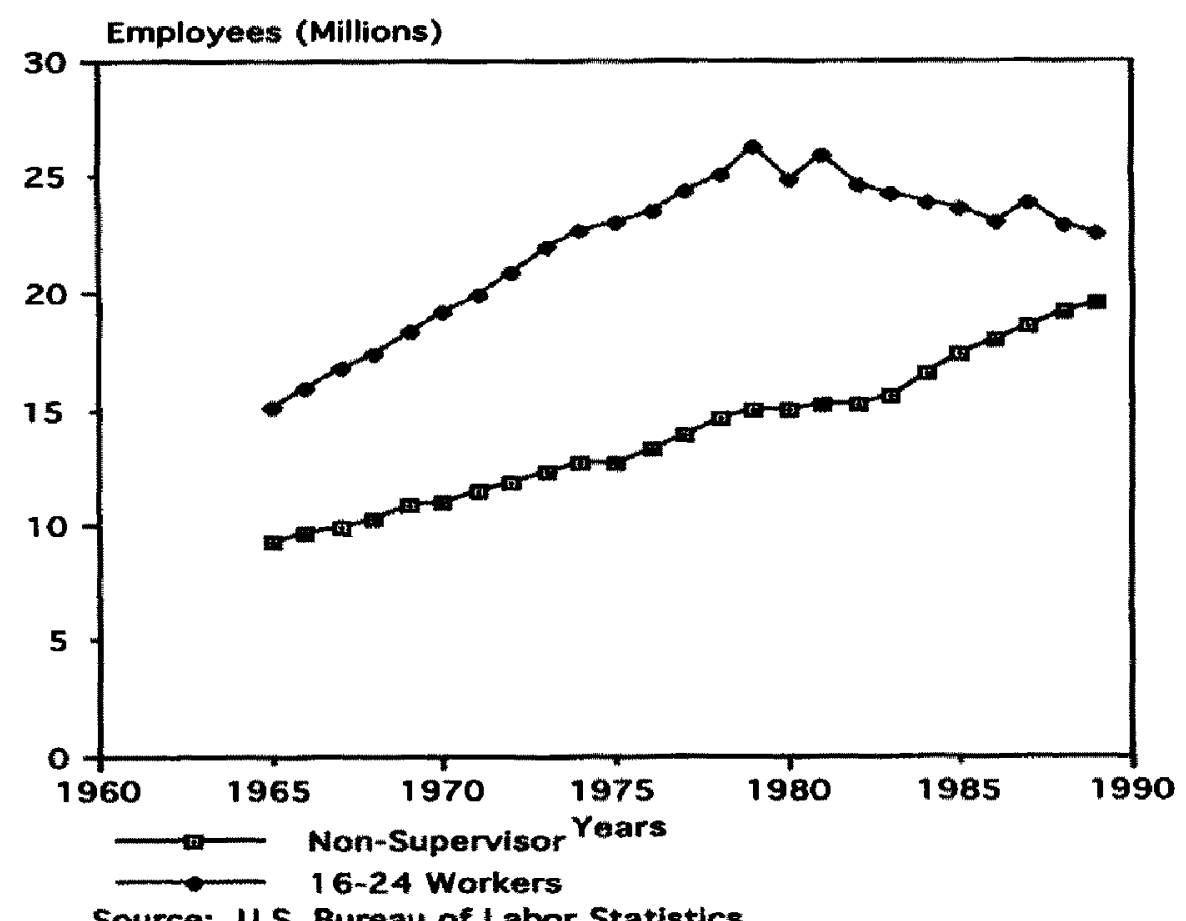

Source: U.S. Bureau of Labor Statistics

findings have indicated that the motives that part-time employees have to work may be different from those of their full-time counterparts [10].

The personnel environment changed dramatically in the $1980 \mathrm{~s}$. The supply of young workers continued to decline throughout most of the decade. As the "baby boom" generation matured and cycled out of the young worker category, they were replaced by a much smaller number of youth from the "baby bust" generation (see Figure 3). At the same time, there was continued growth in the total retail sector which developed a need for additional jobs (see Figure 1). An examination of Figure 1 suggests that the two horizontal lines are converging. Indeed, projections are that the demand for nonsupervisory retail workers will exceed the number of 16-24 year old workers before the turn of the century. The result of this decreased supply and increased demand places retailers in a new competition. Not only will they continue to compete for customers, but retailers will also be faced with competition for personnel.

Unfortunately, the labor environment will continue to worsen through out the 1990 s. As can be noted by examining Figure 3, the pool of young workers will continue to decline through 1995. Although the group of available young workers will have increased slightly in the last half of the decade, this increase will be more than offset by the previously noted continuing demand for entry-level workers. 
Figure 2: Average Hours/Week for Non-Supervisory

Workers in Retail Trade, 1960-1989

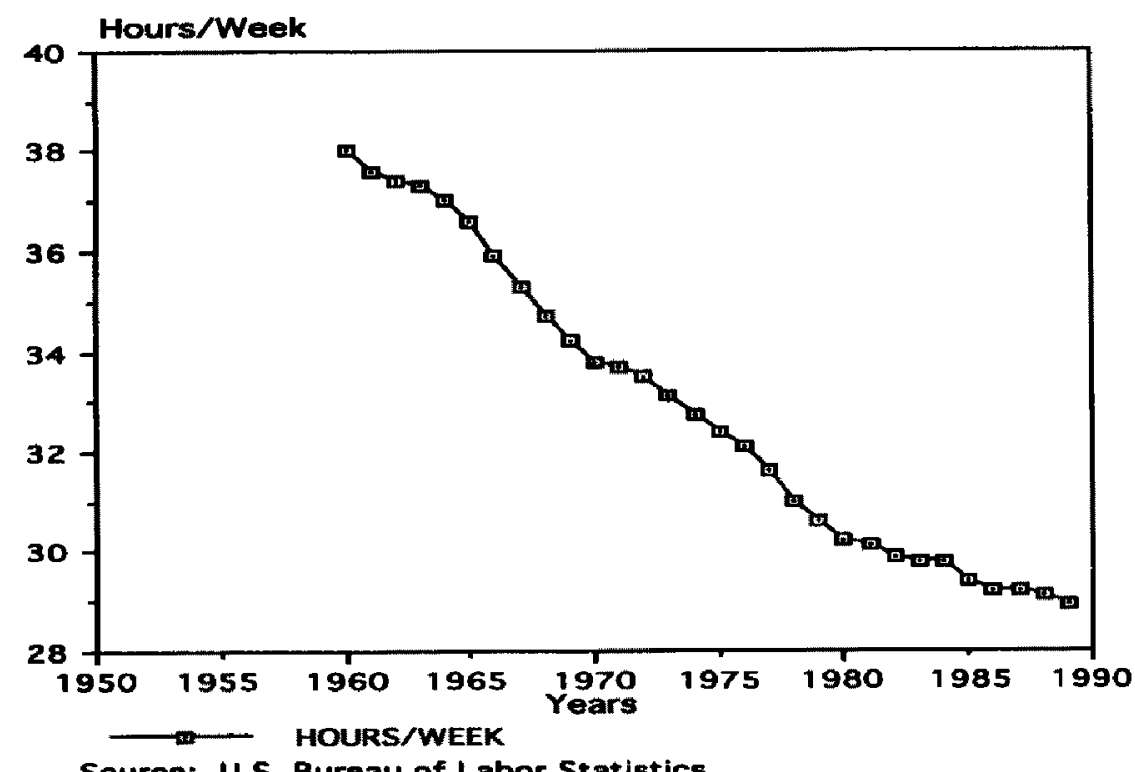

Source: U.S. Bureau of Labor Statistics

\section{Competing for Employees}

The competition for employees has several ramifications for retailers. Not unexpectedly, labor costs have risen dramatically in areas where the shortage is being felt most severely. Specifically, these areas include locales in which the percentage of young people is particularly low (e.g., retirement areas) and/or the overall unemployment rate is low. The latter point is true because retail has typically been used for nonpermanent employment by individuals who temporarily cannot find employment in their chosen industry. Retailers in these areas are faced with increases in both direct and indirect labor costs. The direct costs are higher because the supply/demand labor imbalance is causing the starting rates for even the inexperienced employee to be substantially over the minimum wage rate. Indirect costs have risen as well because the benefit packages being offered-particularly for the part-time worker-have been increased dramatically. Another result is the marked increase in employee turnover. Although turnover is typically higher for all types of retailers, the greatest impact has been felt by fast food retailers. Once again, the rate for part-timers has been particularly high, with some companies facing annual turnover rates in excess of 300 percent [9]. For other industries such as the grocery industry, rates in excess of 100 percent are not uncommon.

The problem has taken an increasing amount of the retail manager's time-not just in looking for solutions, but in order to simply maintain day-to-day operations. Facing these staggering turnover rates, management must spend valuable time recruiting and 


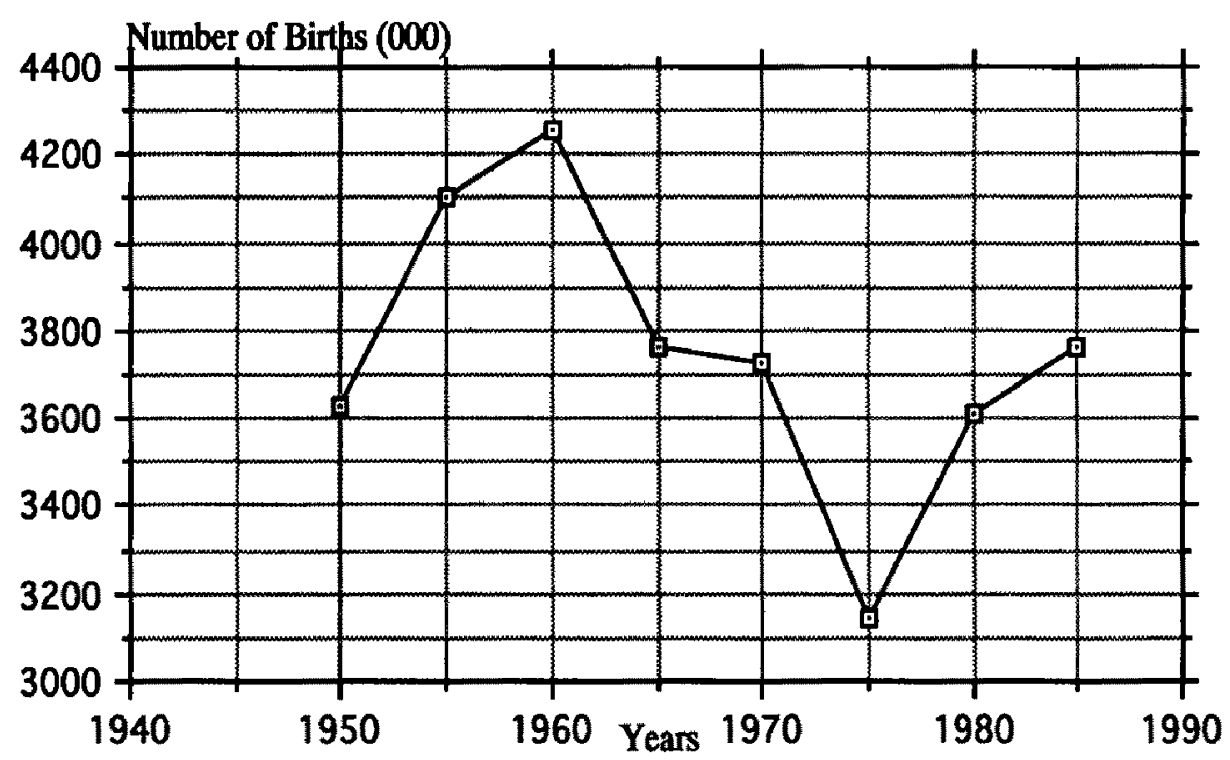

Source: U.S. Bureau of Census

training new employees. Some retailers have gone so far as to pull out of entire areas because of the difficulties associated with staffing their stores. But perhaps the retailer's greatest fear associated with this staffing problem is the unacceptable level of service that an untrained or marginally trained employee will provide to a firm's customers.

In many maturing retail industries, such as department stores, supermarkets, and many specialty stores, the greatest opportunity to differentiate from competition lies in the level of service that accompanies the sale of similar products. However, before carefully constructed strategies to gain a differential advantage by out-servicing competition can be put into place, the personnel turnover problem must be controlled. In fact, if competing firms can do a better job of retaining their personnel-and as a result service their customers with more knowledgeable employees-then a firm may actually find itself at a competitive disadvantage.

There are two ways to approach this turnover problem. The first is to reduce the reliance on personnel. The second is to improve the retention of the new employees that are hired.

Although moving customers toward greater levels of self-service does not appear to be a widespread option, it is one toward which some retailers are moving. For example, several supermarket firms have tested "checkerless" check stands [2]. In what could be described as the ultimate self-service setting, customers not only select the items they wish to purchase, but also scan (i.e., register) their purchases, bag their order, and transport their purchases to their vehicles. Thus customers can complete their entire 
shopping visit, never interacting with an employee except to pay for their groceries. This is an option that will not likely appeal to a large segment of the market.

Most retailers will seek ways to retain a higher percentage of the new employees that they hire. To this point, retailers have pursued a series of options, including increasing the level of compensation, offering more flexible scheduling, increasing educational assistance (e.g., tuition waivers), and offering other assistance such as improved transportation arrangements in order to bus workers into areas where the shortage is particularly severe. Unfortunately, each one of these options can be readily observed and easily duplicated by a firm's competition. If a retailer instituted one of these options and it was well received by potential employees, then the firm would likely soon find the option widely offered in the market. Thus, changes in the options noted above serve to do little more than to up the bidding war (and employer costs) for available entry-level employees.

More successful strategies for the retailer will be those which are effective, but less transparent. The result will be programs that will be harder to emulate. A key here is a better understanding of expectations that a new employee brings to the job. Further, retailers need to understand what, if any, differences may exist in the expectations between the different demographic groups of potential employees. If differences can be isolated, internal strategies can be initiated that will result in the perceived environment more closely matching the expectations that an employee brings to the job. This should lead to personnel who are happier with their employment setting and are thus less likely to leave the organization.

\section{The Study}

Early in the first week of employment, newly hired personnel were asked to complete a questionnaire designed to: (1) prioritize a list of 24 job characteristics by importance to the new employee and (2) record the new hire's initial expectations regarding their employer's ability to provide these characteristics. These characteristics essentially covered three major aspects of work: the job itself (e.g., challenging/interesting work), company environment (e.g., pleasant work environment), and compensation/job security (e.g., good salary). The 24 characteristics of importance were measured on a seven point Likert scale, with the range going from "Very Important" to "Very Unimportant." The employee's perception of the company's ability to provide these same 24 characteristics was also measured on a seven point Likert scale, with options ranging from "Very Likely" to "Very Unlikely." (See Table 4 for a list of the 24 characteristics.) In addition, both the respondent and the employer (at a later date) provided information useful in classifying the respondents into groups.

Job attribute and corresponding company characteristic questions were largely derived from scales and questions that had previously been validated ([5], [7], [8]). In addition, previous tests indicated the measurement scales to have relatively high levels (alpha scores of from .74 to .87 ) of internally consistent reliability [8]. 
Newly hired employees from each of the three retailers were given identical questionnaires. Each of the three retailers was chain operations and responses were gathered from multiple stores at each site. In each case, surveys were administered by company personnel at the individual store site. Respondents were unmonitored and were given time "on the clock" to fill out the questionnaires. Following completion of the survey, respondents sealed the questionnaires in a return envelope addressed to the researchers and sent them to the company mail room where the researchers later picked them up. A total of 796 questionnaires were collected from the three sites; 140 from the department store, 356 from the specialty store, and 300 from the supermarket. Because of the method of data collection, fewer than five percent of potential respondents did not fill out the surveys or filled out so little of it as to render it useless.

Approximately eight weeks following the end of data collection, the researchers obtained employee rosters from each of the companies. The list of new hire respondents was checked against the rosters to determine which of the new personnel had quit and which were still employed. For the department store, 64 of the 119 respondents $(54.6 \%)$ had left the company. In the case of the specialty store, 218 of the 356 respondents (61.2\%) were no longer employed. Finally, 179 of 300 supermarket new hires (59.7\%) were no longer with the firm after eight weeks. Looking at the three samples together, 461 of the $775(59.5 \%)$ had left their respective company before they had been on the job eight weeks.

\section{The Findings}

\section{Demographics}

The demographic profile of the new employees is significantly different among the three retailers (Table 1). Compared to the specialty store and the supermarket, the department store employed a much higher percentage of full-time workers. In addition, their new hires were older (one third were over 24) and had a higher level of education. In contrast, the supermarket was the most dependent of the three retailers on the young (16-24) worker. Correspondingly, their new hires had lower levels of education and were most often single. Additionally, the supermarket operation hired a higher percentage of males. The profile of the specialty store new hire fell between the contrasts established by the department store and the supermarket. For certain characteristics, however, the specialty store new hires seemed to more closely parallel the new supermarket employees. For example, the specialty store was dominated by part-time workers and relied on a higher percentage of younger workers.

A breakdown of the demographic characteristics among the three retailens for those employees who have left their job versus those who remained employed revealed some interesting findings. In six instances there were significant differences between the new hire leavers and the stayers for the individual retailers among the demographic variables studied (see Table 2). These differences supported a general lack of consistency across the three samples of new hires. 


\section{Table 1: Demographic Comparison of New Hires for} Three Different Types of Retailers

\begin{tabular}{|c|c|c|c|}
\hline Variables & $\begin{array}{c}\text { Department Store } \\
\text { (119) }\end{array}$ & $\begin{array}{c}\text { Specialty Store } \\
\text { (356) }\end{array}$ & $\begin{array}{c}\text { Supermarket } \\
(300)\end{array}$ \\
\hline \multicolumn{4}{|l|}{ Employee Type ${ }^{1}$} \\
\hline Part-time & $54.6 \%$ & $\mathbf{9 4 . 4 \%}$ & 98.3\% \\
\hline $\begin{array}{l}\text { Full-time } \\
\text { Sex } 1\end{array}$ & $45.4 \%$ & $5.6 \%$ & $1.7 \%$ \\
\hline Male & $20.2 \%$ & $8.2 \%$ & $45.8 \%$ \\
\hline Female & $79.8 \%$ & $91.8 \%$ & $54.2 \%$ \\
\hline \multicolumn{4}{|l|}{ Marital Status } \\
\hline Single & $70.6 \%$ & $73.9 \%$ & $78.3 \%$ \\
\hline Married & $22.7 \%$ & $18.3 \%$ & $16.7 \%$ \\
\hline Other & $6.8 \%$ & $7.6 \%$ & $5.0 \%$ \\
\hline \multicolumn{4}{|l|}{ Education ${ }^{1}$} \\
\hline Grade School & $0 \%$ & $0.6 \%$ & $0.3 \%$ \\
\hline Some High School & $0 \%$ & $9.7 \%$ & $6.8 \%$ \\
\hline Attending High School & $10.9 \%$ & $32.7 \%$ & $48.6 \%$ \\
\hline High School Graduate & $12.6 \%$ & $27.0 \%$ & $22.0 \%$ \\
\hline Some College & $27.7 \%$ & $12.8 \%$ & $9.5 \%$ \\
\hline Attending College & $23.5 \%$ & $15.1 \%$ & $10.1 \%$ \\
\hline College Degree & $21.0 \%$ & $1.1 \%$ & $2.7 \%$ \\
\hline Some Graduate School & $2.5 \%$ & $1.1 \%$ & $0 \%$ \\
\hline Graduate Degree & $1.7 \%$ & $0 \%$ & $0 \%$ \\
\hline \multicolumn{4}{|l|}{ Age 1} \\
\hline 18 and under & $20.2 \%$ & $47.5 \%$ & $62.4 \%$ \\
\hline $19-24$ & $45.3 \%$ & $30.5 \%$ & $21.5 \%$ \\
\hline $25-35$ & $23.6 \%$ & $14.1 \%$ & $8.7 \%$ \\
\hline $36-50$ & $8.4 \%$ & $5.6 \%$ & $4.7 \%$ \\
\hline 51 and over & $2.5 \%$ & $2.3 \%$ & $2.7 \%$ \\
\hline Average Age & 24.6 yrs. & 22.1 yrs. & 20.9 yrs. \\
\hline \multicolumn{4}{|l|}{ Race } \\
\hline White & $78.8 \%$ & $73.6 \%$ & $79.9 \%$ \\
\hline Black & $16.9 \%$ & $24.2 \%$ & $18.7 \%$ \\
\hline Others & $4.2 \%$ & $2.3 \%$ & $1.3 \%$ \\
\hline
\end{tabular}

${ }^{1}$ Significant differences between the three samples exists at the 0.10 level.

In the case of part-time versus full-time employees, for example, little apparent difference existed between the two categories for the specialty store and the supermarket. For the department store, however, a significantly higher percentage of parttimers left than did full-timers. Although the differences were not significant, a higher percentage of males both in the department store and the specialty store left the orga- 
Fall 1992

Fields \& Nkomo: Slowing the Revolving Door

Table 2: Demographic Comparison of New Hire Leavers and Stayers in Three Different Types of Retailers

\begin{tabular}{|c|c|c|c|c|c|c|}
\hline \multirow{2}{*}{$\begin{array}{l}\text { Variables } \\
\text { Employee Type }\end{array}$} & \multicolumn{2}{|c|}{$\begin{array}{c}\text { Department Store } \\
\text { Leave Stay } \\
\text { (64) (55) }\end{array}$} & \multicolumn{2}{|c|}{$\begin{array}{l}\text { Specialty Store } \\
\text { Leave Stay } \\
\text { (219) (137) }\end{array}$} & \multicolumn{2}{|c|}{$\begin{array}{c}\text { Supermarket } \\
\text { Leave Stay } \\
\text { (175) (125) }\end{array}$} \\
\hline & & & & & & \\
\hline Part-time & 56.9 & $31.5^{\mathrm{a}}$ & 94.5 & 94.2 & 98.9 & 97.5 \\
\hline Full-time & 43.1 & $68.5^{\mathrm{a}}$ & 5.5 & 5.8 & 1.1 & 2.5 \\
\hline \multicolumn{7}{|l|}{ Sex } \\
\hline Male & 21.5 & 18.5 & 8.7 & 7.3 & 41.9 & $51.7^{b}$ \\
\hline Female & 78.5 & 81.5 & 91.3 & 92.7 & 58.1 & $48.3^{b}$ \\
\hline \multicolumn{7}{|l|}{ Marital Status } \\
\hline Single & 80.0 & $59.3^{\mathrm{c}}$ & 71.6 & 78.1 & 77.7 & 79.2 \\
\hline Married & 16.9 & $29.6^{\mathrm{c}}$ & 18.8 & 17.5 & 16.8 & 16.7 \\
\hline Other & 3.1 & $11.2^{c}$ & 9.6 & 4.4 & 5.6 & 4.2 \\
\hline \multicolumn{7}{|l|}{ Education } \\
\hline Grade School & 0.0 & $0.0^{d}$ & 0.9 & 0.0 & 0.6 & $0.0^{\mathrm{d}}$ \\
\hline Some High School & 0.0 & $0.0^{d}$ & 11.5 & 6.7 & 8.5 & $4.2^{\mathrm{d}}$ \\
\hline Attending High School & 12.3 & $9.3^{d}$ & 27.6 & 40.7 & 46.6 & $51.7^{d}$ \\
\hline High School Graduate & 10.8 & $14.8^{d}$ & 29.0 & 23.7 & 23.9 & $19.2^{d}$ \\
\hline Some College & 23.1 & 33.3 $3^{d}$ & 13.4 & 11.9 & 10.2 & $8.3^{d}$ \\
\hline Attending College & 32.3 & $13.0^{d}$ & 14.3 & 16.3 & 6.3 & $15.8^{d}$ \\
\hline College Degree & 21.5 & $20.4^{d}$ & 1.8 & 0.0 & 4.0 & $0.8^{d}$ \\
\hline Some Graduate School & 0.0 & $5.6^{\mathrm{d}}$ & 1.4 & 0.7 & 0.0 & $0.0^{d}$ \\
\hline Graduate Degree & 0.0 & $3.7^{d}$ & 0.0 & 0.0 & 0.0 & $0.0^{d}$ \\
\hline \multicolumn{7}{|l|}{ Age } \\
\hline 18 and under & 27.7 & $11.1^{\mathrm{e}}$ & 44.5 & 52.2 & 58.7 & 68.1 \\
\hline $19-24$ & 46.1 & $42.6^{\mathrm{e}}$ & 22.6 & 27.2 & 26.2 & 14.3 \\
\hline $25-35$ & 21.6 & $27.8^{e}$ & 15.6 & 11.8 & 8.4 & 9.2 \\
\hline $36-50$ & 4.6 & 12.96 & 4.1 & 8.1 & 4.5 & 5.0 \\
\hline 51 and over & 0.0 & $5.6^{\mathrm{e}}$ & 3.2 & 0.7 & 2.2 & 3.4 \\
\hline Average Age (years) & 22.2 & 27.6 & 22.4 & 21.6 & 20.8 & 21.1 \\
\hline \multicolumn{7}{|l|}{ Race } \\
\hline White & 76.9 & 81.1 & 72.0 & 75.9 & 81.6 & 77.5 \\
\hline Black & 16.9 & 17.0 & 25.7 & 21.9 & 16.8 & 21.7 \\
\hline Others & 6.2 & 1.9 & 2.3 & 2.2 & 1.7 & 0.8 \\
\hline
\end{tabular}

aSignificant differences $(p<.01)$ between leavers and stayers for employee type

bSignificant differences $(p<.10)$ between leavers and stayers for sex

Significant differences $(p<.05)$ between leavers and stayers for marital status

dSignificant differences $(p<.05)$ between leavers and stayers for education

eSignificant differences $(\mathrm{p}<.01)$ between leavers and stayers for age 
nizations. For the supermarket, significantly higher percentages of females left the company. Similar conflicts were apparent for the balance of the variables. A significantly higher percentage of single employees left the department store while the findings were in the opposite direction for the new hires of the other two retailers. The department store had a significantly higher percentage of new hires attending college leave the company, while a significantly higher percentage of college students stayed with the supermarket. Conversely, though both the specialty store and the supermarket had higher percentages of young workers (under 24) stay with the organizations, the department store had a significantly higher percentage of this group leave the company. Finally, in the case of race, although none of the differences were significant, there were different directions in the findings.

\section{Characteristics of Importance}

Table 3 indicates characteristics of importance for which there were significant differences between the leavers and the stayers for each of the three retail organizations. As can be noted, there was much diversity in the results across the three retail samples. For the supermarket respondents, no differences between the leavers and the stayers could be found. In the specialty store, the two groups differed only in their rating of the importance of Showing Effective Performance and Medical Benefits. However, in the department store, the leavers and the stayers recorded significant dif-

\section{Table 3: Characteristics of Importance \\ Significant Differences Between Leavers and Stayers by Retailer}

Characteristic

DEPARTMENT STORE

Good Co-workers

Challenging/Interesting Work

Good Salary

Training Programs Available

Chance to Advance Rapidly

Good Career Path

Medical Benefits

SPECIALTY STORE

Show Effective Performance

Medical Benefits

SUPERMARKET

No Significant Differences

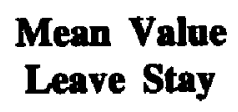

$\begin{array}{ll}1.50 & 1.87^{2}\end{array}$

$1.631 .35^{3}$

$\begin{array}{ll}1.83 & 1.39^{2}\end{array}$

$\begin{array}{ll}1.17 & 1.83^{2}\end{array}$

$2.251 .78^{3}$

$2.26 \quad 1.60^{2}$

2.541 .681

$1.50 \quad 1.67^{3}$

$\begin{array}{ll}2.13 & 2.49^{2}\end{array}$
Ranking

Leave Stay

$4 \quad 19$

$\begin{array}{ll}9 & 1\end{array}$

142

$\begin{array}{ll}17 & 17\end{array}$

$\begin{array}{ll}19 & 16\end{array}$

2010

$21 \quad 12$

$5 \quad 10$

2021

${ }_{1}^{1}$ Significant differences between leavers and stayers were found at the $P<.01$ level

2 Significant differences between leavers and stayers were found at the $P<.05$ level

${ }^{3}$ Significant differences between leavers and stayers were found at the $P<.10$ level 
ferences on seven of the 24 characteristics. The stayers viewed six of the seven characteristics as having significantly more importance. However, the Good Co-workers characteristic was considered by the leavers to have more importance.

The relative ranking of the characteristics (with 1 having the highest rating) is also included in Table 3. Substantial differences in the order in which leavers and stayers rated the importance of the characteristics can be seen on a majority of the entries.

Consistency in the rating and relative ranking of the characteristics for the leavers across the three retailers was considered in Table 4. Respondents from each of the three retailers indicated similar ratings for characteristics that had both highest and lowest relative rankings. Characteristics that leavers rated as having the greatest level of importance (Boss I Can Work With, Enjoyable Type of Work, and Pleasant Work Environment) were consistent across the three samples. Similarly, leavers from each

\section{Table 4: Characteristics of Importance for Leavers Mean Score and Ranking by Retailer}

\section{Characteristic}

Boss I Can Work With

Enjoyable Type Work

Pleasant Work Environment

Good Co-Workers

Company's Good Reputation

Opportunity to Learn

Desirable Store Location

Show Effective Performance

Challenging/Interesting Work

Opportunity to Use Abilities

Job Fits My Lifestyle

Flexible Work Schedule

Job Security

Good Salary

Variety of Activities

Good Fringe Benefits

Training Programs Available

Appropriate Sized Company

Chance to Advance Rapidly

Good Career Path

Medical Benefits

Individual Work Freedom

Prestigious Job Title

Tuition Waiver Opportunity

\begin{tabular}{|c|c|c|c|c|c|}
\hline \multicolumn{2}{|c|}{$\begin{array}{l}\text { Department } \\
\text { Store }\end{array}$} & \multicolumn{2}{|c|}{$\begin{array}{l}\text { Specialty } \\
\text { Store }\end{array}$} & \multicolumn{2}{|c|}{$\begin{array}{l}\text { Super- } \\
\text { Market }\end{array}$} \\
\hline Mean & Rank & Mean & Rank & Mean & Rank \\
\hline 1.43 & 1 & 1.19 & 1 & 1.46 & 1 \\
\hline 1.45 & 2 & 1.47 & 4 & 1.73 & 4 \\
\hline 1.46 & 3 & 1.43 & 2 & 1.61 & 2 \\
\hline 1.50 & 4 & 1.55 & 7 & 1.81 & 10 \\
\hline 1.55 & 5 & 1.67 & 10 & 1.74 & 5 \\
\hline 1.57 & 6 & 1.44 & 3 & 1.77 & 7 \\
\hline 1.57 & 7 & 1.65 & 9 & 1.66 & 3 \\
\hline 1.62 & 8 & 1.50 & 5 & 1.81 & 9 \\
\hline 1.63 & 9 & 1.63 & 8 & 1.88 & 12 \\
\hline 1.65 & 10 & 1.69 & 11 & 1.97 & 13 \\
\hline 1.74 & 11 & 1.86 & 14 & 2.27 & 19 \\
\hline 1.75 & 12 & 1.53 & 6 & 1.77 & 8 \\
\hline 1.80 & 13 & 1.75 & 13 & 1.85 & 11 \\
\hline 1.83 & 14 & 1.73 & 12 & 1.75 & 6 \\
\hline 1.89 & 15 & 2.01 & 15 & 2.28 & 20 \\
\hline 1.92 & 16 & 2.03 & 16 & 2.09 & 17 \\
\hline 2.17 & 17 & 2.32 & 21 & 2.39 & 21 \\
\hline 2.17 & 18 & 2.12 & 19 & 2.03 & 14 \\
\hline 2.25 & 19 & 2.06 & 17 & 2.05 & 15 \\
\hline 2.26 & 20 & 2.07 & 18 & 2.09 & 16 \\
\hline 2.54 & 21 & 2.13 & 20 & 2.27 & 18 \\
\hline 2.63 & 22 & 2.96 & 24 & 2.86 & 24 \\
\hline 2.81 & 23 & 2.55 & 22 & 2.72 & 22 \\
\hline 3.05 & 24 & 2.84 & 23 & 2.85 & 23 \\
\hline
\end{tabular}

NOTE: There were no significant differences between the three samples. 
sample ranked Individual Work Freedom, Prestigious Job Title, and Tuition Waiver Opportunity as having the least importance.

Although there was generally more variation among the three samples in the "midrange" variables, some merit additional discussion. The rating for the Good Salary variable was remarkably consistent-with scores ranging from 1.73 to 1.80 for the three samples. The rating for Flexible Work Scheduling was similar although the range was wider because respondents who ultimately left the specialty store indicated a slightly higher level of importance for the variable. Other variables which exhibited a narrow range were Desirable Store Location and Job Security.

\section{Company Characteristics}

Differences between the leavers' and the stayers' perceptions of the particular retailer's ability to provide the characteristic were examined for each of the 24 variables. Significant differences for each of the three samples (if any) are reported in Table 5. Although responses should be expected to differ from retailer to retailer, at issue is whether a relationship between the perceptions of incoming employees and the decision to leave the company after a short time might be suggested.

The results follow a pattern similar to that found for the characteristics of importance. Once again, there were no significant differences between the leavers and stayers for the supermarket respondents. Two differences were found for the specialty store sample. Leavers indicated a lower expectation that the specialty store would be able to provide flexible scheduling. Unexpectedly, the leavers also indicated a higher level of expectation that training programs would be available.

\section{Table 5: Company Characteristics Significant Differences Between Stayers and Leavers}

\section{Characteristic}

Department Store

Training Programs Available

Good Fringe Benefits

Medical Benefits

Good Career Path

Specialty Store

Flexible Work Schedule

Training Program Available

Supermarket

No Significant Differences

${ }_{1}^{1}$ Significant differences at the $P<.05$ level

${ }^{2}$ Significant differences at the $P<.10$ level
Mean Value

Leave Stay

$\begin{array}{ll}2.09 & 1.69^{1}\end{array}$

$\begin{array}{ll}2.65 & 2.15^{1}\end{array}$

$\begin{array}{ll}2.91 & 2.26^{1} \\ 3 & 2.03\end{array}$

$\begin{array}{ll}3.05 & 2.43^{1}\end{array}$

\begin{tabular}{ll}
1.71 & 1.491 \\
\hline &
\end{tabular}

$\begin{array}{ll}1.71 & 1.49 \\ 2.88 & 3.18^{2}\end{array}$

\section{Ranking}

Leave Stay

115

$17 \quad 16$

$\begin{array}{ll}19 & 17\end{array}$

$20 \quad 18$

$4 \quad 2$

$15 \quad 18$ 
More differences were observed between the leavers and the stayers in the department store sample. Significant differences for Training Programs Available, Good Fringe Benefits, Medical Benefits, and Good Career Path were found. In each case, leavers were more pessimistic that the particular characteristic would be provided by the company.

\section{Conclusions}

In the research at hand, the demographic characteristics of the newly hired employees who remained on the job after eight weeks were not consistent among the three retailers studied. While some of the differences may be explained by the fact that the three retailers are hiring employees, as a group, who have slightly differing characteristics, this retention inconsistency develops more questions than it answers. For example, in the case of employee type, clearly the department store placed more emphasis on the hiring of full-time employees than did the other two retailers. This effort is consistent with actions of other department store operations [1]. However, explanations for the numerous other differences are not as apparent. In the case of the opposite findings in the retention of student new hires for the department store versus the other retailers, no clear reason surfaces. None of the three retailers provided any special incentive (e.g., tuition waiver) to this group. A possible explanation, unsubstantiated by any data in the present study, as to why both the specialty store and the supermarket do a better job retaining student new hires than does the department store may lie in the companies' approach to work scheduling. If, for example, the department store is very rigid in their scheduling, students may find after a short period of employment that this is not consistent with their needs. Given the present labor market, other employers with more flexible scheduling practices will be sought out.

This, and other similar explanations for conflicting characteristics, can be offered to explain the differences. However, the analysis of differing demographic characteristics was not the focus of this research. Indeed, the degree and the number of differences found were unexpected. As a result, the research was not directed at determining why newly hired employees were reacting differently in different retail environments. This should be the objective of future research. The value of this research is: (1) the development of knowledge of characteristics that are important to the employee at the time of hire which may be utilized to improve new hire retention and (2) the realization that while many differences do exist across retailers, some possible generalizations are suggested for all retail new hires.

Identifying and incorporating the employee's characteristics of importance into employment policy may help retailers retain a higher percentage of their new hires. For example, individuals who left each of the three retailers after a short period of time apparently came to that organization driven by characteristics about their jobs that were oriented around the present working environment. These workers do not apparently place a great deal of importance on future considerations. Rather, they are most interested in doing work that they enjoy, in a nice environment, and for a supervisor with whom they are compatible. 
Characteristics that retail management have traditionally considered as keys to retaining entry-level new hires-a good salary and flexible work scheduling-do not appear near the top of the characteristics of importance of any of the three groups of new hire leavers. Relative to the other characteristics, the new hire leavers apparently do not view these two factors as critical to continued employment. Retailers will likely find this result surprising, since these are areas which most often receive attention when companies attempt to improve their new hire retention rate.

The relative importance of characteristics may differ between new hire leavers and stayers for a particular retailer. In the case of the department store, the new hire stayers cited several factors which indicated an interest with the level of personal development in their job. The top characteristics selected by the new hire leavers, as was discussed above, centered around their present work environment.

Examining the new hire's perception of the retailers' provision of the characteristics of importance could be of value in two ways. First, any differences in the perceptions between the new hire leavers and the new hire stayers could be identified. The newly hired personnel who ultimately left the department store entered the job with a higher level of pessimism regarding the firm's ability to provide their characteristics of importance. Apparently, the formal training by the department store was not able to overcome the higher concerns on the part of this group of new hires. It seems logical that this impacted on the individual's decision to leave the company. A second possible benefit for the retailer is the determination of the degree that the new employees perceive that the company will provide the various characteristics of importance. This knowledge would be particularly beneficial for the highly ranked characteristics. When new employees enter a job feeling that there is little likelihood that the organization will provide certain key characteristics, their retention may be difficult. If these new hires later discover other employment opportunities that they perceive better provide their key characteristics, then it is likely that job change will result. A labor seller's market magnifies this problem.

\section{Managerial Implications}

The results of this study of newly hired entry-level retail employees suggest that while it might be beneficial for the department store, or the specialty store, or the supermarket to profile their retained new hires to identify characteristics that contribute to their retention, these characteristics apparently do not uniformly bold across retail classifications. Thus, there is no single profile for an entry-level worker applicable to all retail industries. Further, whether or not profiles within a particular industry are valid is not known and should be the subject of future research. This emphasizes the importance of retailers understanding their employees. If simple demographic characteristics for employees who typically stay in their jobs longer can be identified, then these retailers can improve retention by utilizing improved hiring practices.

Several traditional assumptions about employee retention are negated by this study. As a group, entry-level new hires apparently do not view their jobs in retailing from 
a career perspective. This employee group places little relative importance on those characteristics that are critical for career development. Thus, retailers who go to the expense of developing and maintaining intermediate job levels for their salespeople may not be appealing to as many entry-level personnel as may have previously assumed. The traditional methods of increasing salary do not hold a high relative position of importance-particularly for the younger worker. As a result, many retailers who increase the wage rate to this level of worker expecting to significantly improve their retention may be disappointed. Similarly, offering a flexible work schedule appears to have a low relative level of importance to these workers. Factors other than simply bumping up their wage rate and scheduling these people to work when they want to work appear more critical in the retention decision.

An analysis of the characteristics of importance for the new hire leavers suggests that training may hold the key for all retailers to realize increased retention for this group. The training is not for the workers; however, it is for their immediate supervisors. The uniform importance that the leavers placed on having a boss they could work with stresses the importance of the presence of "people skills" in these first-level managers. While the objectives of the organization cannot be sacrificed, neither can the needs of the employees. Thus, these supervisors must be able to blend the expectations of the employee with the expectations of the retailer. Unfortunately, this management talent does not necessarily come with the job title. Since this supervisory level is often used by retailers as an entry-level management position, these managers typically have little or no previous management experience. As a result, retailers may be setting themselves up for high levels of turnover among entry-level salespeople. In the present job market, retailers may no longer be able to accept the results of "on-the-job" management training as newly appointed managers hone their personnel skills. Immediate and thorough training must quickly convert autocratic managers to "team managers" before their previous style has had a chance to impact the entry-level salespeople.

In some retail situations, isolating differences between the characteristics that are important to new hire stayers versus new hire leavers can lead to the development of programs that may reduce the percentage of new hire leavers. Where clear differences are found to exist, retailers have the opportunity to develop and implement additional programs aimed at the characteristics that are most important to the group that had previously been leaving the organization. As long as these programs supplement and do not replace existing efforts, then retailers should be more effective in meeting the needs of this group. Implicit in this program development is the importance of not misleading the employee. Employees who feel they have received accurate information are more likely to remain with the organization than those who perceived that they have received inaccurate information about their job (3).

A comparison of new employees' characteristics of importance with their impression of how a company will provide these characteristics can be extremely helpful in directing training emphasis for future employees. When viewing new employees' perceptions relative to their characteristics of importance, decisions can be made as to whether to address the significant differences through new programs (when the differ- 
ence is valid) and/or through emphasis on employee training (when the difference is the result of a misconception) or to ignore the difference (when either the cost of the program is too great or the characteristic is judged to have insignificant importance). Regardless of the decision, the important issue is recognizing the difference that exists. To help determine if differences in the perceptions of new hires are present, it may be helpful to query applicants about what they know about the company and its characteristics during the job interview. Misperceptions can be corrected at this stage of the employment process with little or no direct costs.

Perceptions regarding the provision of characteristics of importance may be found to differ significantly between the new hire stayers and the new hire leavers. When this is noted, it's an indication that not only are leavers entering employment with a more pessimistic view of the company, but this view is not being corrected in the course of the retailer's formal training of its new employees.

Improving the retention of new employees in retailing bas been, and remains, a complex issue. Retailers can pursue simple actions, however, that should yield a better reiention rate for their new employees. First, the retailer should develop a demographic profile of the employees who have maintained employment over a certain period of time versus a profile of those who have left the company. Significant differences should be incorporated into future hiring strategies. Second, it may be valuable to identify the job characteristics which are most important to the two groups of new hires. If differences exist between the two groups, then programs may be developed in order to better address the important characteristics of the individuals who have been leaving the company. Finally, it should be beneficial for the retailer to identify how incoming employees perceive the company's ability to provide the characteristics which are important to the new employees. When significant differences are found on key characteristics, then the retailer must decide (1) if action is warranted and (2) when needed, the action that would be most appropriate. The result will be a higher level of retention of new employees, corresponding lower training costs, and greater profitability. The key is whether or not employers understand the newest additions to their most valuable resource.

The need to better understand the entry-level retail worker is moving from a managerial luxury to a managerial necessity. Firms that understand and develop corresponding programs that are consistent with the expectations of their new employees will enjoy a higher retention rate. The result will be a more knowledgeable group of personnel who are most often the ones who interact with the firm's customers. Retailers who do not recognize this need will find their revolving door of personnel cycling through their organization to be turning even faster in the future.

\section{References}

1. Bergman, Joan. "Who's Selling the Merchandise in Your Store?" Stores, (January), Vol. 28 (1984), p. 113. 
2. Blumenthal, Robin Goldwyn. "Self-Service Goes to the Checkout Counter As Supermarkets Test Automated System." Wall Street Journal, (November 13, 1986), p. A70.

3. Caldwell, David F. and O'Reilly III, Charles A. "The Impact of Information on Job Choices and Turnover." Academy of Management Journal, (1985), No. 4, p. 940.

4. Haugen, Steven E. "The Employment Expansion in Retail Trade, 1973-1985." Monthly Labor Review, (August 1986), pp. 9-15.

5. Harris, Michael M. and Fink, Laurence S. "A Field Study of Applicant Reactions to Employment Opportunities: Does the Recruiter Make a Difference?" Personnel Psychology, Vol. 40 (1987), pp. 765-784.

6. Jackofsky, Ellen F., Salter, James and Peters, Lawrence H. "Reducing Turnover Among Part-Time Employees." Personnel, (May 1986), pp. 41-42.

7. Posner, Barry Z. "Comparing Recruiter, Student, and Faculty Perceptions of Important Applicant and Job Characteristics." Personnel Psychology, Vol. 34 (1981), pp. 329-339.

8. Powell, Gary N. "Effects of Job Attributes and Recruiting Practices on Applicant Decisions: A Comparison." Personnel Psychology, Vol. 37 (1984), pp. 721-732.

9. Serlen, Bruce. "The Changing Face of the Franchise Worker." Franchise, (May-June 1986), pp. 12-16.

10. Thurik, Roy and Van Der Wijst, Nico. "Part-Time Labor in Retailing." Journal of Retailing, Vol. 60, No. 3, (Fall 1983), pp. 62-80. 